\title{
Strain modal analysis of the vibrating screen upper beam
}

\author{
Zerong Zhang \\ College of Electromechanical Engineering, Qingdao University of Science and Technology, \\ Qingdao,China \\ E-mail:cba1998@126.com
}

Keywords: vibrating screen; upper beam; strain modal analysis; modal frequency

Abstract: The comparisons of the displacement and strain modal parameters were researched for the vibrating screen upper beam with fatigue damaged crack. The results show that the modal frequencies and the displacement mode shapes have little difference between intact and damaged upper beam, but the strain mode shapes have obviously mutation for the fatigue damaged upper beam. Therefore a damaged indicator is defined as the rate of strain modal change between damaged and intact beam. The rate of strain modal change increases with the increasing damaged degree of the vibrating screen upper beam. The prediction of the damaged degree of the upper beam can provide reference for maintenance forecast of the vibrating screen upper beam, which can ensure safe and reliable operation of the vibrating screen.

\section{Introduction}

The large linear vibrating screen is used for screening in mining, metallurgy, chemical and other industries [1].The working conditions of the vibrating screen is complex which leads to the structural fatigue damage is serious. Therefore fatigue damage monitoring is useful for predicting the remaining service life of the vibrating screen [2]. The modal analysis is an effective and reliable nondestructive testing technology. The structure modal parameters such as frequency and vibration mode is determined by the structure of the mass, stiffness and damping. The structural damage will inevitably cause the change of modal parameters, so the damaged location and damaged degree of the structure can be determined according to the change of the modal parameters. Cawley first proposed to using the natural frequency of the structure as indicators for damaged identification[3]. Li analyzed the corresponding relationship of the strain modal parameters and the displacement modal parameters[4]. Kranjc analyzed the experimental strain mode and the displacement mode, concluded that the strain modal parameters is more sensitive in vibration fatigue analysis and damaged identification[5]. In this research, we built sensitive and reliable damage index of the vibrating screen beam based on strain modal analysis, which can predict the damaged extent and location of the beam.

\section{Damage identification theory based on the modal parameters}

The vibrating screen is a multiple degrees of freedom system, the free vibration equation is

$$
\mathbf{M} \ddot{\mathbf{x}}+C \dot{\mathbf{x}}+\mathbf{K} \mathbf{x}=0
$$

where $\boldsymbol{M}, \boldsymbol{C}$ and $\boldsymbol{K}$ are the mass, the damping and the stiffness matrices, respectively.

From Eq. (1) we can get

$$
\left(\mathbf{K}-\omega_{i}^{2} \mathbf{M}\right) \boldsymbol{\Phi}_{i}=0
$$

where $\omega_{i}$ is the $i$ th modal frequency, $\boldsymbol{\Phi}_{i}$ is the $i$ th mode shape.

According to finite element theory, the relationship between strain mode shape $\boldsymbol{\Psi}^{\varepsilon}$ and displacement mode shape $\boldsymbol{\Phi}$ is

$$
\boldsymbol{\Psi}_{i}^{\varepsilon}=\mathbf{B} \boldsymbol{\Phi}_{i}
$$


When the vibrating screen structure generates fatigue crack, its stiffness, frequency and mode shape is different from the intact structure, which is

$\left((\mathbf{K}+\Delta \mathbf{K})-\left(\omega_{i}+\Delta \omega_{i}\right)^{2} \mathbf{M}\right)\left(\mathbf{\Phi}_{i}+\Delta \mathbf{\Phi}_{i}\right)=0$

Accordingly, the strain modal parameters is varied,

$\left((\mathbf{K}+\Delta \mathbf{K})-\left(\omega_{i}+\Delta \omega_{i}\right)^{2} \mathbf{M}\right) \mathbf{B}^{-1}\left(\Psi_{i}^{\varepsilon}+\Delta \Psi_{i}^{\varepsilon}\right)=0$

In fact, the fatigue crack damage mainly leads to the local stiffness varied, so the variation of the modal frequencies and displacement mode shapes are small, while the variation of the strain mode shape is large .

In order to improve the effectiveness and reliability of the fatigue damage diagnosis result, we recommend the strain modal change ratio $(S R)$ as the damage index:

$$
S R=\frac{\Delta \Psi_{i}^{\varepsilon}}{\Psi_{i}^{\varepsilon}}
$$

\section{Displacement and strain modal analysis of the vibrating screen upper beam}

Selects the $27 \mathrm{~m}^{2}$ large linear vibrating screen as the research object, the sieving size is $7.5 \mathrm{~m} \times 3.6$ $\mathrm{m}$, as shown in figure 1, the inner diameter of the upper beam is $164 \mathrm{~mm}$, outside diameter is $180 \mathrm{~mm}$, wall thickness is $8 \mathrm{~mm}$, beam length is $3.6 \mathrm{~m}$, using 40 steel material, its yield strength is $294 \mathrm{MPa}$, ultimate strength is $549 \mathrm{MPa}$, elastic modulus is $209 \mathrm{GPa}$, density is $7.81 \mathrm{x} 103 \mathrm{~kg} / \mathrm{m}^{3}$, poisson's ratio is 0.27 .

Since the middle of the upper beam is the fatigue crack initiation and propagation region, so the simulated fatigue crack is assumed at the midpoint of the No. 2 upper beam in FEM model, the fatigue crack is assumed $1 \mathrm{~mm}$ wide along the longitudinal direction, as shown in figure 2.Considering the vibrating screen upper beam is thin-walled circular tube structure, the shell element is adopted in finite element meshing, element SHELL181 is applied to the vibrating screen upper beam with the adaptive meshing method.
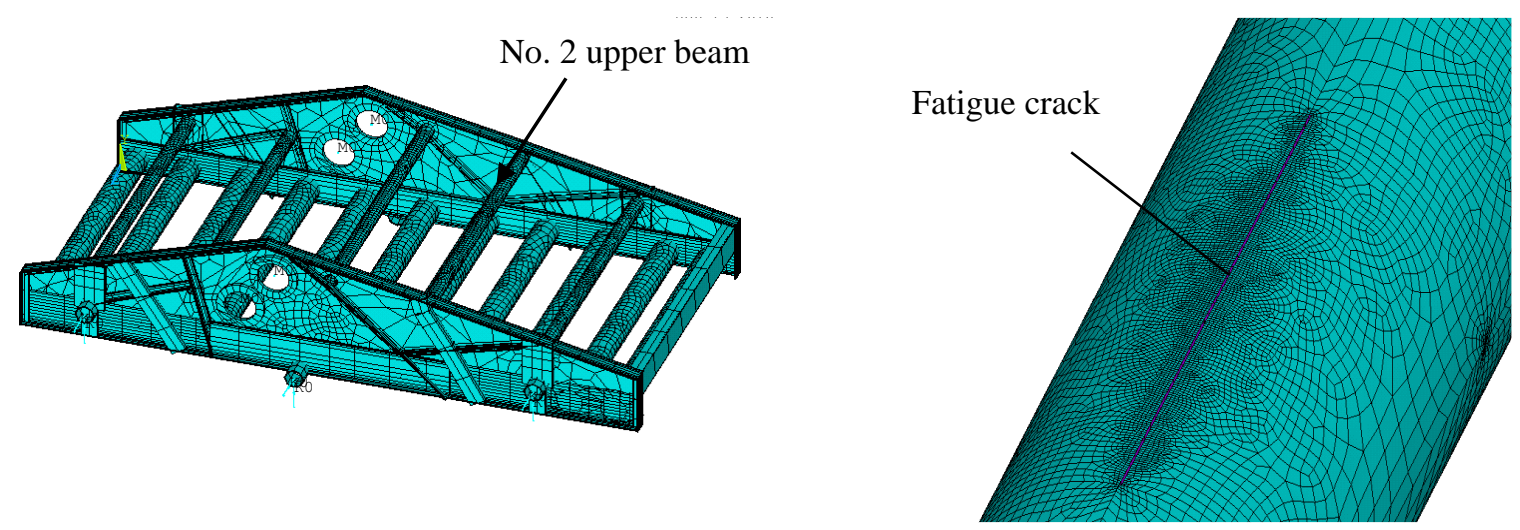

Fig. 1 Finite element model of the vibrating screen Fig. 2 The simulated fatigue crack of the No.2 beam

Because the upper beam is thin-walled circular tube structure, The critical crack length of the upper beam can be calculated by Eq. (7)

$$
a_{c}=\frac{1}{\pi}\left(\frac{K_{I C}}{f \sigma_{\max }}\right)^{2}
$$

For the materials of the upper beam is 40 carbon steel, $K_{\mathrm{IC}}=70.9 \mathrm{MPa} \sqrt{\mathrm{m}}, f=1.53, \sigma_{\max }=27.8 \mathrm{MPa}$, the critical crack length $a_{\mathrm{c}}$ is equal to $885 \mathrm{~mm}$.

To analyze the relationship between the modal parameters and the fatigue residual life of the upper beam, the fatigue damaged degree is assumed ten percent to ninty percent for displacement and strain modal analysis. SHELL181 element is adopted to improve the adaptive meshing, divided 10368 nodes and 10296 elements.Using Block Lanczos method to extract the modal frequencies and vibration modes, the first 5 modal frequencies of the intact and damaged upper beam are shown in 
table 1 , the relative deviation is $\eta=\left(f_{p}-f_{c}\right) / f_{p}$. The modal frequencies of the damaged upper beam is smaller than the intact upper beam. When the damaged degree is $60 \%$, the maximum relative deviation is $6.62 \%$. When the damaged degree is $30 \%$, the relative deviation is less than $8.28 \%$. The change ratio of the modal frequencies is small, so if the modal frequency is adopted as indicators of damage detection, the accuracy is low.And it is difficult to determined the damaged location of the vibrating screen upper beam.

Table 1. The modal frequencies of the intact and damaged beam

\begin{tabular}{llllll}
\hline \multirow{2}{*}{ mode } & $\begin{array}{l}\text { intact beam } \\
f_{p}[\mathrm{~Hz}]\end{array}$ & $\begin{array}{l}\text { damaged 30\% } \\
f_{c}[\mathrm{~Hz}]\end{array}$ & $\begin{array}{l}\text { relative deviation } \\
\eta[\%]\end{array}$ & $\begin{array}{l}\text { damaged } 60 \% \\
f_{c}[\mathrm{~Hz}]\end{array}$ & $\begin{array}{l}\text { relative deviation } \\
\eta[\%]\end{array}$ \\
\hline 1 & 81.32 & 80.49 & 1.02 & 80.47 & 1.05 \\
2 & 213.47 & 212.55 & 0.43 & 208.07 & 2.53 \\
3 & 400.39 & 400.38 & 0.00 & 392.08 & 2.08 \\
4 & 629.61 & 629.21 & 0.00 & 628.98 & 0.10 \\
5 & 786.88 & 721.69 & 8.28 & 734.82 & 6.62 \\
\hline
\end{tabular}

The displacement and strain modal parameters of the finite element model were calculated, the second order of the displacement mode shape is shown in Figure 3(a), the strain mode shape is shown in Figure 3(b) when the beam damaged 60 percent. Due to the upper beam central fatigue crack, the largest strain modal amplitude produces at the midddle region of the vibrating screen upper beam.
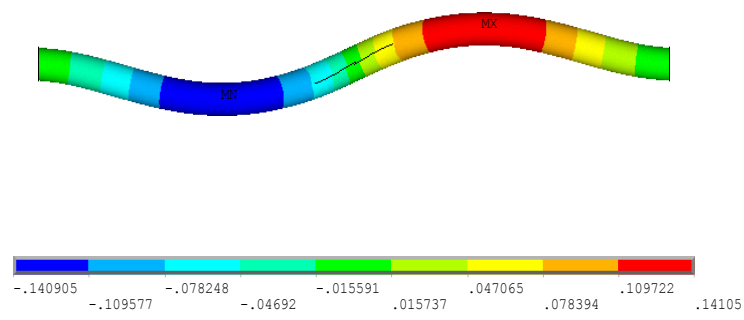

(a). The second displacement mode shape
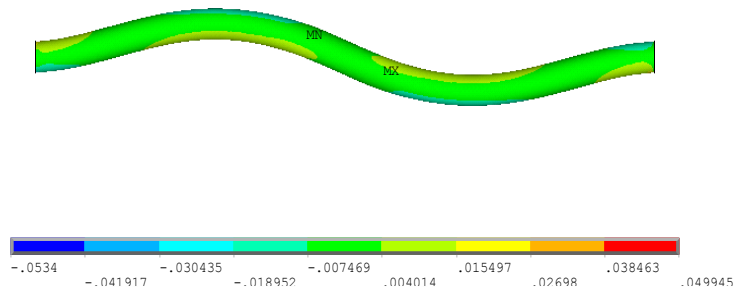

(b). The second strain mode shape

Fig. 3 The second mode of the beam damaged 60 percent

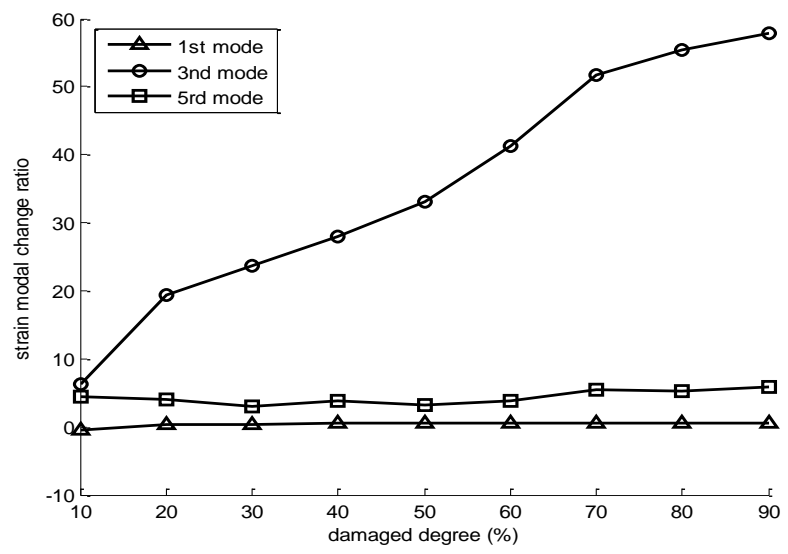

Fig.4 The strain modal change ratio versus different damaged degree

The change ratio of the first three bending strain modes versus different damaged degree is shown in figure 4 . With the damaged degree increased, the change of first and fifth order strain mode are small which imply it is not sensitive to fatigue damage. But the third order strain mode shows the tendency of linear increase with the increase of damaged degree.So the beam fatigue damage 
diagnosis index can be defined as the effective strain modal change rate, the effective modal is the third order of the bending modes of the vibrating screen upper beam.

\section{Conclusions}

The displacement and strain modal analysis of the large linear vibrating screen upper beam was studied, the results show that the modal frequencies change is small between the intact and damaged upper beam, the displacement modes also have no obvious change, but the strain modal shape of the fatigue damaged upper beam produced mutation peaks.Analysis found that effective strain modal change rate of the vibraitng screen upper beam increases linearly with the fatigue damaged crack growth. The sensitive and reliable damage index of the vibrating screen beam based on strain modal analysis is bulit, which can predict the damaged extent and location of the vibrating screen upper beam.

\section{Acknowledgements}

Financial support for this work provided by the national natural science foundation of China(Grant no.51074094) and Shandong Provincial Natural Science Foundation of China (Grant no. ZR2015EM035) are gratefully acknowledged.

\section{References}

[1] Hou Yongjun, Wang Luyou, Ma Jun. Free Vibration Analysis of Shale Shaker Laminated Flat-screen. Journal of Mechanical Engineering, Vol.51, Issue 23(2015), p.60-67.

[2] Liu Wen-guang, Chen Guo-ping. Coupling analysis for vibration and fatigue of a cracked cantilever beam Journal of vibration and shock, Vol.30, Issue 5(2011), p. 140-144.

[3] P. Cawley, R.D. Adams. The Location of Defects in Structures From Measurements of Natural Frequencies. Journal of Strain Analysis for Engineering Design, Vol.14, Issue 2(1979), p. 49-57.

[4] Li Debao. A general review on several fundamental points of experimental strain/stress modal analysis. Journal of Vibration and Shock, Issue 1(1996), p. 13-17.

[5] T. Kranjc, J. Slavič, M. Boltežar. A comparison of strain and classic experimental modal analysis.Journal of Vibration and Control, Vol.22 (2016), p. 371-381. 